\title{
Developing employability in higher education music
}

\section{Dawn Bennett}

Research and Graduate Studies, Curtin University, Perth, Australia

\begin{abstract}
The development of employability in higher music education concerns students, musicians, educators, administrators and funding bodies, and yet employability is both impossible to measure and poorly defined. This paper sets the context for a set of short papers that explore employability from the perspective of music. Because many of the issues they raise have relevance across the creative industries, this paper discusses research that positions them within this broader context. The paper highlights the need for both the functional (how-to) aspects of employability and those that are cognitive: development of students' cognitive dispositions and the capacities to engage as professionals. As such, the paper argues that employability requires collaborative action on three fronts: enhancement of the ways in which employment outcomes are defined and measured; initiatives that engage students in career- and life-relevant activities; and advocacy work that realigns stakeholder perceptions of graduate work and employability itself.
\end{abstract}




\section{Keywords}

graduate employment, arts, tertiary education, creative industries, creative workforce

\section{Introduction}

Most higher education institutions accept the need to help students gain the skills, knowledge and personal attributes required to negotiate the initial stages of their careers (Mietzner and Kamprath, 2013; Oliver et al., 2014). Far from the traditional world of a full-time position with a single employer, however, music graduates are among a growing number of higher education graduates who enter ill-defined, complex labour markets with rapidly transforming employment contexts. These graduates commonly experience multiple entry attempts, multiple concurrent roles and the need to selfmanage their career development (Bennett and Bridgstock, 2014). Arguably, of all graduates they have the greatest need for support both during and after graduation. This might include mentorship, short courses, career counselling and access to resources such as equipment, sheet music or rehearsal space. Such opportunities are increasingly seen as an extension of core business for higher education institutions (Bennett, Richardson and MacKinnon, 2015).

One of the difficulties for higher music education is that portfolio careers - those featuring multiple concurrent roles-are too complex to be 
measured by traditional metrics such as national graduate destinations surveys and census collections (Gollmitzer and Murray, 2009), which Hartley (2005) attributes to the sheer variety of scale, economic activity and organisation of the creative sector.

Most graduate data collections ignore multiple roles in favour of the position in which the most time is spent: the main occupation at a particular point in time. Further, respondents seeking work are assumed to be unemployed, whereas they may be seeking additional or more desirable work from a position of under-employment. This is despite rates of underemployment being similar to those of unemployment across most developed economies. As a result, government demands for higher education institutions to define and demonstrate graduates' successful entry into the labour market are confounded by inadequate graduate and labour market data, and the assumption that success is represented by a single, full-time position.

The short papers that follow focus on the theme of employability, with perspectives from the US, Europe and Australia on approaches to working with music students, new graduates and established practitioners. Angela Beeching from the Manhattan School of Music in the US considers the needs and interests of audiences. By sharing examples of initiatives designed to encourage this understanding amongst students, Beeching argues that for 
students to understand their audiences they need first to understand community, business and entrepreneurial thinking: core aspects of a musician's practice.

Continuing the entrepreneurial theme, Nicole Canham from the University of Queensland in Australia suggests that developing artists need to think of themselves as mavericks and makers in order to be creatively independent. Canham illustrates her argument with the stories of eight independent, classically trained musicians whose artistic thinking has enabled them to address the challenges of career construction in music. Angeliki Triantafyllaki also focuses on the developing artist. Writing from the University of Athens in Greece, and emphasising the need for lifelong, life-wide learning as identified by Mietzner and Kamprath (2013), Triantafyllaki employs case studies of emerging artists to illustrate the creative transfer of knowledge and skills through collaborative work, identity (re)construction and life-wide experiences.

All three papers introduce new thinking and examples of innovative practice which have considerable relevance for higher music educators as we strive to prepare students for their lives and careers. To set the context, this paper outlines the characteristics of the creative industries workforce and the characteristics of work likely to be encountered by music graduates. 


\section{Extant datasets and empirical studies}

Few music students think about the music industry as part of an economically strong sector; and yet music is one of the largest creative industries (UNCTAD, 2008). Graduate employment data suggest that the graduates of arts and creative industries programs, including music, have among the poorest graduate outcomes of any program (Graduate Careers Council of Australia, 2012). Concerned that reporting is insufficiently nuanced, even when using the extant data, Bennett, Richardson and MacKinnon (2015) analysed the 2013 Australian graduate data, which included 83,000 graduates, and confirmed that the poor graduate outcomes are indisputable when only full-time employment is considered. However, deeper analysis confirmed that visual and performing arts graduates engage in a range of employed and self-employed roles including both part-time and full time work. When these forms of work were included, the employment outcomes of all students emerged as relatively similar (Figure 1). 


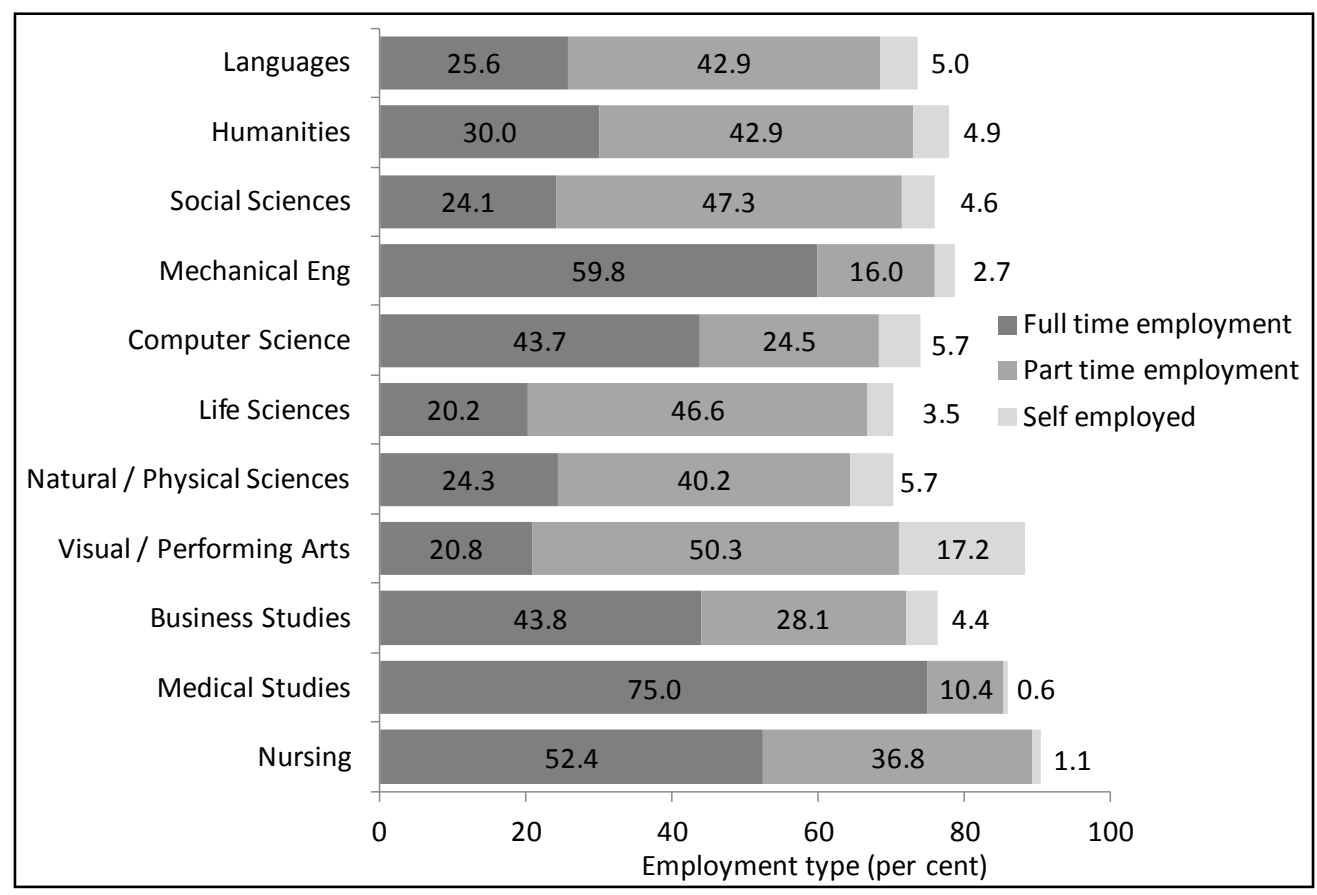

Figure 1: Employment outcomes (\%), Graduate Destinations Survey 2013

(Data supplied by the Australian Government Department of Education)

The 'creative trident' of occupations (Higgs, Cunningham and Bakhshi, 2008) is one of the most commonly used models for analysis of limited extant national datasets. The trident describes creative workers as:

- specialist creatives employed in core creative occupations within the creative industries (for example, orchestral musicians);

- embedded workers employed in core creative occupations within other industries (for example, musicians working in therapeutic settings); or 
- support workers employed in other occupations within the creative industries (for example, musicians in retail or business roles).

Creative workers whose work is mostly outside the trident are defined as non-creative workers. Limitations include a reliance on census data, the classification of teaching 'non-creative' because it falls within another economic sector, and the allocation of a single trident mode for each worker.

In seeking more specificity for governments and educators, and to create sufficient evidence for researchers to integrate large-scale datasets with empirical research data, researchers have over the past decade begun to amass data on the characteristics and economic circumstances of creative work across a number of the creative industries. These analyses have included foci on 'good and bad' work (Fitzgerald, Rainnie and Bennett, 2011); old and new sectors including digital economies (Hesmondhalgh and Baker, 2011); the characteristics of creative work (Bennett et al., 2014; Smith and McKinley, 2009); flexibility and autonomy (Banks, 2010); and creativity itself (Hesmondhalgh 2008). The studies have added to the body of evidence that illustrates the characteristics and economic circumstances of creative workers, including the inclusion of multiple roles both within and beyond the artform. 
To give an example of how empirical data can extend understanding of the creative workforce, Figure 2 illustrates the intersections of specialist, support, embedded and 'non-creative' roles reported by 182 creative workers in Australia (Bennett et al., 2014). As mentioned, large-scale data collections enable the reporting of each individual worker against a single creative trident mode. The empirical research in this study enabled all roles within each worker's portfolio to be mapped against the trident. The results illustrate that a single mode is inadequate when reporting creative work: of these workers, $83 \%$ engaged in more than one trident mode and only $36 \%$ reported a single role.

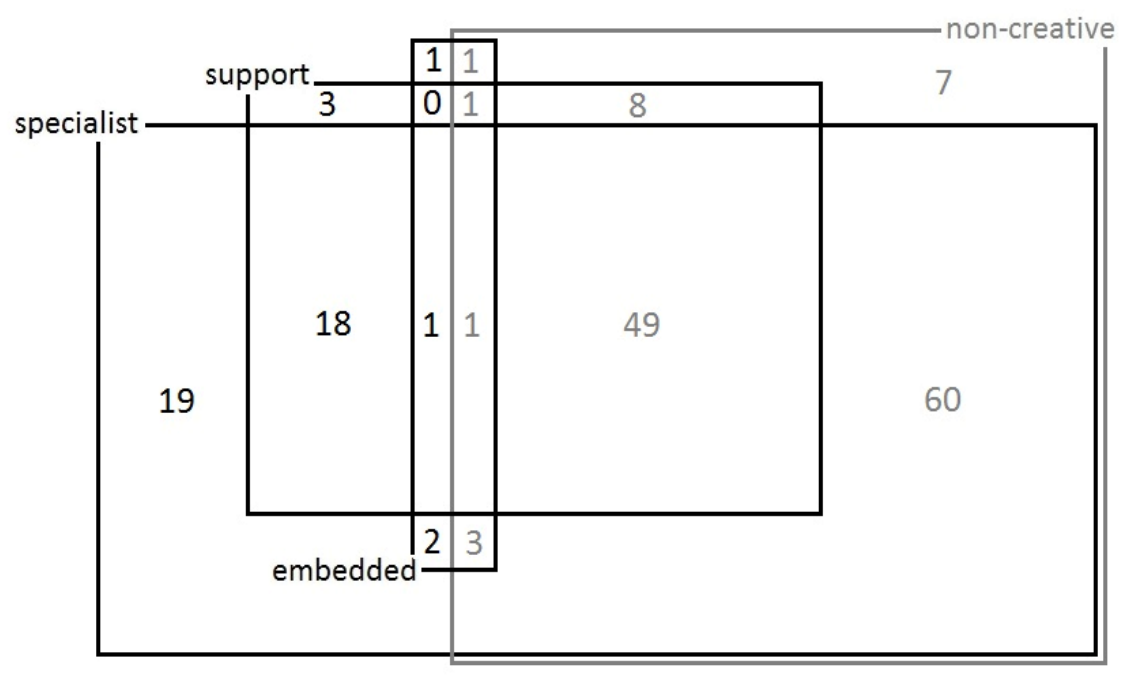

Figure 2: Multiple roles in the creative trident (count) as reported by 182 creative workers in Australia (Bennett et al. 2014: 164) 


\section{Making sense of creative work: the key points}

Internationally, few musicians hold full time, permanent positions in the major arts companies (see Beeching, 2010; Bennett, 2008; Perkins, 2012). Hennekam and Bennett's creative workforce research (forthcoming) across The Netherlands, Canada and Australia highlights the prevalence of multiple concurrent roles and also the amount of unpaid work (between $30 \%$ and $47 \%$ of all work). Hennekam and Bennett have also identified a notable increase over time in temporary employment and an associated increase in job insecurity. An additional feature of creative work is the high rate of selfemployment (Center for an Urban Future, 2008), and performing artists specifically are up to five times more likely than other workers to be selfemployed (Throsby \& Zednik, 2010).

Both Bennett et al's 2014 study of Australian creative workers and Hennekam and Bennett's studies (forthcoming; in review) of creative workers in the Netherlands and Canada have found that precarious work such as that described above persists throughout the career lifecycle and across creative disciplines and genres. Neither research team found significant differences between the average number of hours in each role, between sexes or age, between career stage, or between the prevalence of employed/self-employed work and contractual or casual work. In essence, from graduation and throughout the career: 
Creative workers manage their own careers, work typically in small firms and on an ad-hoc basis, gain employment through networks, and stay employable by learning new skills and ensuring that they are visible to the market. (Bennett, 2015, n.p)

These factors illustrate that remaining employable requires creative workers such as musicians to manage careers and businesses, professional learning and networks, industry awareness and innovative thinking. As seen at Figure 2, where 130 of the 183 artists reported non-creative work, noncreative work (and the trident includes teaching in this mode) is an important element of a creative worker's portfolio.

Although many music graduates aspire to make a living through the creation or expression of their creative work, a music career almost always means the inclusion of work located outside music and the creative industries, particularly when teaching is categorised as an outside role. Noncreative industries work can take the form of work that is temporary, it can be long-term undesirable work sustained because of its consistency, and it might be work that is both consistent and desirable. It can also be the primary source of income and the primary use of time: Cunningham and Higgs (2010), for example, using the trident model, found that $40.5 \%$ of 
Australian musicians, singers or composers were employed principally outside the creative industries.

\section{Concluding comments: implications for educators}

Graduate dissatisfaction in creative industries programs, including those in the arts, focuses in the main on insufficient preparation for work. This dissatisfaction relates to weak or non-existent links between higher education and industry, limited opportunities for industry experience and lack of industry awareness (Guile 2006), poor technological skills (Bartosova, 2011), lack of small business skills, weak professional networks (Bennett, Richardson and MacKinnon, 2015), little awareness of legal and contractual rights and obligations (Haukka, 2011), insufficient knowledge of multiple genres (Bennett 2008), and little knowledge about how to work with people from different cultural backgrounds (Jeffcutt, 2004).

In their work with over 700 creative workers in the Netherlands, Australia and Canada, Hennekam and Bennett (forthcoming) found business acumen to be the aspect most needed by new graduates. Specifically, practitioners advocated that higher education programs in the creative industries must incorporate: 
- a more hands-on approach to prepare for the realities of creating and managing a business;

- flexible placements and internships both in and outside the curriculum; and

- preparation to maintain skills, competencies and industry knowledge as self-directed, self-funded learners.

Hennekam and Bennett assert that there is now sufficient evidence to define essential fundamentals across higher education. These essential fundamentals may resonate with higher music educators and include:

... a basic knowledge of legal rights and responsibilities, small business skills, management and technological acuity, personal attributes that enable graduates to confidently express, market and apply their skills and knowledge, and entrepreneurial thinking.

In higher education, discussions about employability most often focus on the functional aspects of becoming employed, that is, a solid curriculum vitae, proficiency in interviews or auditions, and perhaps a website containing examples of work. This focus is exacerbated by the simplistic metrics discussed earlier as the results are aligned with base funding. It 
follows that the most common forms of institutional employability assistance concern job applications, résumé writing and the development of a portfolio of evidence including experience, achievements or repertoire. Behind the functional aspect of employability, however, lies the development of individual learners with unique strengths and talents, aspirations and interests. This individuality is evident in the papers contributed by Canham, Beeching and Triantafyllaki, whose case study examples illustrate why adult learners learn more effectively and at a deeper level when their learning is accepted as being relevant to their future lives and work (Knowles, 2005).

Fostering students' professional identities along cognitive dimensions with respect to their dispositions and capacities to engage as professionals concerns development of the whole individual; it is this development that enables informed musical mavericks to transfer and acquire the skills and knowledge they need to survive and thrive in music. The themed papers highlight the potential for advocacy work that fosters cognitive growth by showcasing diverse role models, explicitly valuing employability within the curriculum, and informing reforms to the existing measures by undertaking empirical research. 


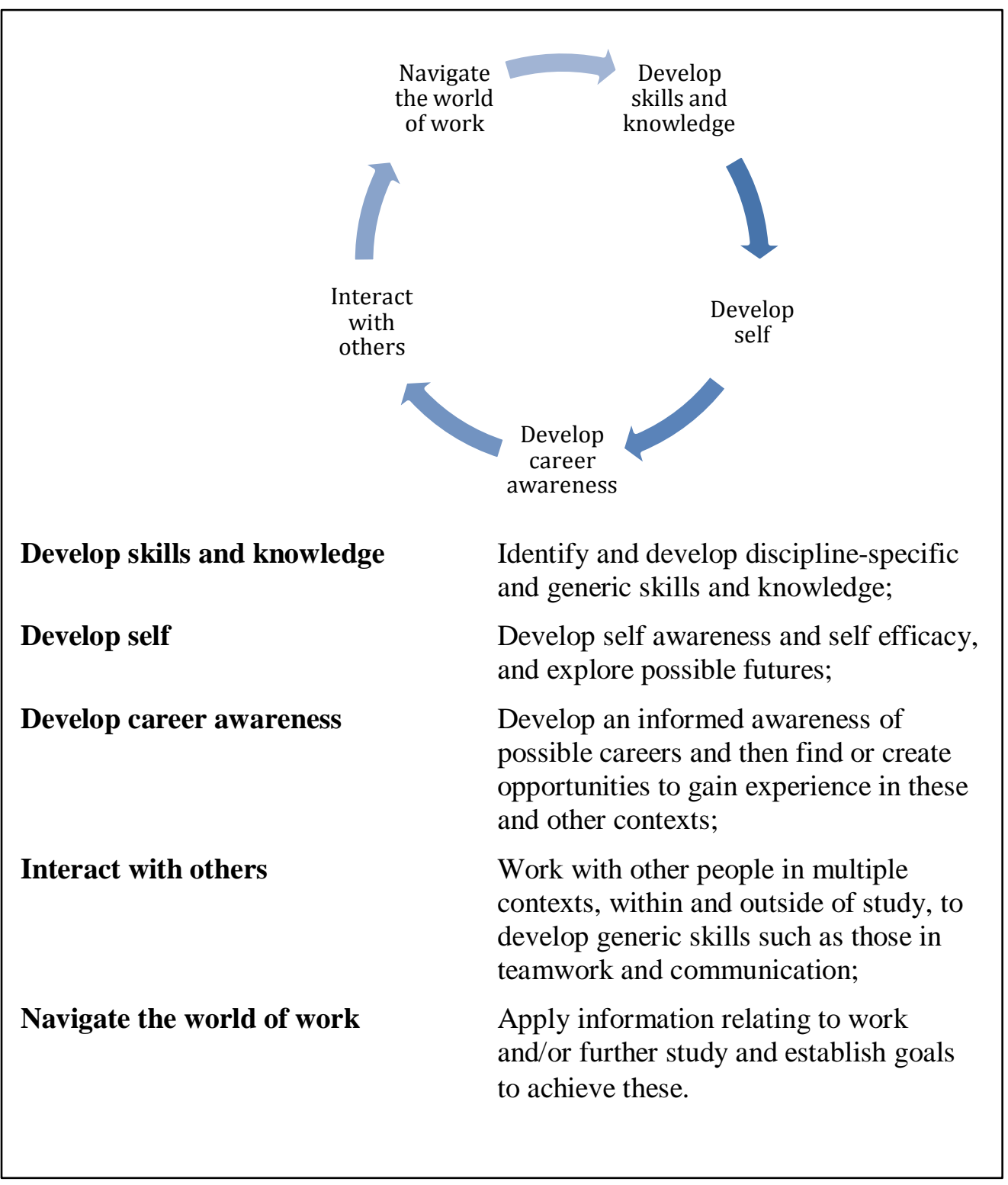

Figure 3: Employability development framework (Bennett, Richardson and MacKinnon 2015) 
Adopting the principle of action research: plan - act-observe - reflect, employability development frameworks such as that shown at Figure 3 are designed to help educators respond to the emerging needs of students and to maximise opportunities for the development of cognitive employability such as that evidenced in the short papers. The need for such frameworks has become increasingly clear over the past decade alongside recognition that developing employability for music higher education graduates requires collaborative action on three fronts: enhancement of the ways in which employment outcomes are defined and measured; initiatives that engage students in career- and life-relevant activities; and advocacy work by educators, significant others and industry to re-align stakeholder perceptions of graduate work and employability. These are the issues that most concern music educators, leaders and advocates.

\section{References}

ARC Centre of Excellence for Creative Industries and Innovation (CCI) (2013) Australian Creative Economy Report Card 2013. Brisbane: CCI.

Banks M (2010) Craft labour and creative industries. International Journal of Cultural Policy 16: 305-321. 
Bartosova D (2011) The future of the media professions: current issues in media management practice. International Journal on Media Management 13(3): 195-203.

Beeching A (2010) Beyond Talent: Creating A Successful Career In Music. New York: Oxford University Press.

Bennett D (2008) Understanding The Classical Music Profession: The Past, The Present And Strategies For The Future. Aldershot: Ashgate Publishing Limited.

Bennett D (2009) Dance Careers: Beyond Performance To The Real World Of Work. Journal of Dance Education 9(1): 27-34. Bennett, D 2015, Industry Snapshot: The Performing Arts. Available from <www.graduateemployability.curtin.edu.au >. [12 May 2015].

Bennett D, Coffey J, Fitzgerald S, Petocz P and Rainnie A (2014) Beyond the Creative: Understanding the Intersection of Specialist and Embedded Work for Creatives in Metropolitan Perth. In: Hearn G, Bridgstock R, Goldsmith B and Rodgers J (eds) Creative Work Beyond the Creative 
Industries: Innovation, Employment, and Education Cheltenham: Edward Elgar Publishing, pp. 158-174.

Bennett D, Richardson S and Mackinnon P (2015) Enacting Strategies for Graduate Employability: How Universities Can Best Support Students to Develop Generic Skills. Sydney: Australian Government Office for Learning and Teaching.

Center for an Urban Future (2008) Creative New York, New York: City Futures Inc.

Cunningham S and Higgs P (2010) What's Your Other Job? A Census Analysis of Arts Employment in Australia. Melbourne: Australia Council for the Arts.

Fitzgerald S, Rainnie A and Bennett D (2012) Cultural labour in Australia: towards a renewed research agenda. In: $26^{\text {th }}$ Australian and New Zealand academy of management conference, Perth, Australia, July. Perth: ANZAMC.

Gollmitzer M and Murray C (2009) Work Flows and Flexicurity: Canadian 
Cultural Labour in the Era of the Creative Economy. Vancouver: Center for Expertise on Culture and Communities.

Graduate Careers Council of Australia (2012) Graduate Destinations 2011: the Report of the Graduate Destination Survey. Melbourne: Graduate Careers Council of Australia.

Guile, D (2006) Access, learning and development in the creative and cultural sectors: from "creative apprenticeship" to "being apprenticed". Journal of Education and Work 19(5): 433-445.

Hartley J (2005). Creative Industries. In Hartley J (ed) Creative Industries. Massachusetts: Blackwell Publishing, pp. 1-40.

Hennekam S and Bennett D (in review) Creative industries work across multiple contexts: Common themes and challenges. Personnel Review (submitted July 2015).

Hennekam S and Bennett D (forthcoming) Self-management of work in the Netherlands creative industries. International Journal of Arts Management (accepted June 2015). 
Hesmondhalgh D (2008) Cultural and creative industries. In: Bennett T and Frow J (eds) The Sage Handbook of Cultural Analysis. London: SAGE, pp. $552-570$.

Hesmondhalgh D and Baker S (2011) Creative Labour: Media Work in Three Cultural Industries. London: Routledge.

Higgs P, Cunningham S and Bakhshi H (2008) Beyond the Creative Industries: Mapping the Creative Economy in the United Kingdom. London: Nesta.

Jeffcutt P (2004) Knowledge relationships and transactions in a culture economy. Media International Australia incorporating Culture and Policy 112: $67-82$.

Knowles MS, Holton III EF and Aswansu R (2005) The Adult Learner (6th edn). London: Butterworth Heinemann.

Mietzner D and Kamprath M (2013) A competence portfolio for professionals in the creative industries. Creativity and Innovation Management 22(3): 280-294. 
Oliver D, Freeman B, Young C, Yu S and Verma G (2014) Employer

Satisfaction Survey. Sydney: Workplace Research Centre.

Perkins R (2012) Rethinking 'career' for music students: identity and vision.

In Bennett D (ed) Life in the Real World: How to Make Music Graduates

Employable. Illinois: Common Ground Publishing, pp. 11-26.

Smith C and McKinlay A (2009) Creative industries and labour process analysis. In McKinlay A and Smith C (eds) Creative Labour: Working in the Creative Industries. Basingstoke: Palgrave Macmillan, pp. 3-28.

Throsby D and Zednik A (2010) Do You Really Expect to Get Paid? An Economic Study of Professional Artists in Australia. Melbourne: Australia Council for the Arts.

UNCTAD (2008) Creative Economy Report 2008. New York: UDCP. 